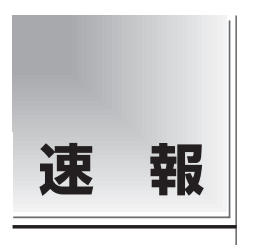

論文受付

2013 年 5 月 10 日

論文受理

2013 年 7 月 30 日

Code No. 300

\section{SPM を用いたパーキンソン病と 進行性核上性麻痺の比較による 特徵的な血流低下の検出}

原田権吾 佐伯裕志 松谷栄二 沖田 泉

\section{緒 言}

近年, 解剖学的標準化を応用した脳血流の画像解析法 が開発され, 脳核医学に臨床応用されている. Statistical parametric mapping $(\mathrm{SPM})^{1,2}$ は, ロンドンのハマースミス 病院の Friston らによって, positron emission tomography (PET)を用いた脳賦活試験のために開発された研究用 のツールである. 現在, 解剖学的標準化を応用した脳 核医学の新しい解析法として single photon emission computed tomography (SPECT)に応用されている. 次 に, 進行性核上性麻瘏 (progressive supranuclear palsy: PSP)は 1964 年に Steele ら ${ }^{3}$ によって報告された神経変 性疾患である, 臨床症状として, 運動障害は歩行が不 安定になり, Parkinson's disease(PD)によく似た歩行異
常も出現し，転倒を伴うのが特徵である．無動・筋強剛 は四肢より頸部や体幹に強く現れ(体軸性固縮)，しばし ば頸部ジストニアによる首が後屈して強直する症状が みられ，有力な手がかりとなり確定診断になる場合があ る. 眼球運動障害は上下方向, 特に下向きの随意的眼 球運動が障害される。発症初期には症状がみられず, 発症後 2〜3 年たってから出現することが挙げられる. また，構音障害，嚥下障害が伴うことがある，認知症 症状があった場合, 判断力は低下し見当識障害, 物忘 れが比較的軽症なのが特徵である。大脳皮質はそれほ ど冒されないが皮質下の神経核が冒されることで，特 徵的な神経症状が現れる。神経症状が PD と相違した 場合，鑑別が問題となる疾患であり，進行して特異的

\title{
Detection of Cerebral Hypoperfusion Using Single Photon Emission Computed Tomography Image Analysis and Statistical Parametric Mapping in Patients with Parkinson's Disease or Progressive Supranuclear Palsy
}

\author{
Kengo Harada, ${ }^{*}$ Hiroshi Saeki, Eiji Matsuya, and Izumi Okita \\ Department of Radiology, Hiroshima City Hospital
}

Received May 10, 2013; Revision accepted July 30, 2013

Code No. 300

\section{Summary}

Purpose: We carried out differential diagnosis of brain blood flow images using single-photon emission computed tomography (SPECT) for patients with Parkinson's disease (PD) or progressive supranuclear paralysis (PSP) using statistical parametric mapping (SPM) and to whom we had applied anatomical standardization. Materials and methods: We studied two groups and compared brain blood flow images using SPECT (N-isopropyl-4-iodoamphetamine $\left[{ }^{123} \mathrm{I}\right]$ hydrochloride injection, $222 \mathrm{MGq}$ dosage i.v.). A total of 27 patients were studied using SPM: 18 with PD and 9 with PSP; humming bird sign on MRI was from moderate to medium. Results: The decline of brain bloodstream in the PSP group was more notable in the midbrain, near the domain where the humming bird sign was observable, than in the PD group. Conclusions: The observable differences in brain bloodstream decline in the midbrain of PSP and PD patients suggest the potential usefulness of this technique's clinical application to distinction diagnosis.

Key words: single photon emission computed tomography (SPECT), statistical parametric mapping (SPM), progressive supranuclear palsy, Parkinson's disease, humming bird sign on magnetic resonance imaging (MRI)

*Proceeding author 
な症状が鑑別された時は難しくないが, 初期症状では 難易を要している。決定的な所見として, magnetic resonance imaging(MRI)では humming bird sign ${ }^{4}$ ，四丘 体槽の拡大, 第 3 脳室の拡大が挙げられる. しかし, 明瞭に確認されるのは病期の進んだ中期から末期であ る。また，SPECTでは早期から前頭葉の血流低下が現 れる報告がある。その他の画像診断として, Parkinson’s syndrome (PS)を生ずる疾患は PD との鑑別の場合ため, 3-ヨードベンジルグアニジン $\left({ }^{123} \mathrm{I}\right)$ 注射液を用いた交感 神経 scintigraphy が施行される。筋集積の低下を示 さないのが特徴であるが, incidental Lewy body disease (ILBD)や糖尿病・心疾患を伴った場合，集積低下は明 らかな所見とならないことがある，以上から，診断に難 易を要する場合が多く，早期に発見されることは臨床 症状が主であり, 経過観察にて進行性の病状より確定 診断に至ることが多い，今回，われわれは画像診断の 一助として SPECT 画像より PSP の特徵的な血流低下 領域を検出したので報告する。

\section{1. 方 法}

\section{1-1 生命倫理について}

本研究は生命倫理に十分な配慮し, 当院の倫理審査 委員会の承認(25-32)を得た研究であることを本文中に 明記する。 また，個人情報の保護のために必要な処置 を講じ，個人を特定できないように解析を行い，有用 な結果は研究に使用することを合意のもとで施行して いる.

\section{1-2 対 象}

$\mathrm{PD}$ 群：18 例(男女比 4：5，55 78 歳，平均年齢 68.6 歳, Hoel\&Yahr 重症度分類 2 4, MRI\&CT 所見：特異的な異常なし)

PSP 群：9例(男女比 $3: 1,65 \sim 77$ 歳, 平均年齢 71.6 歳, humming bird sign 軽度～中等度)

\section{1-3 解剖学的標準化と parameter}

標準化の基準となる塩酸 N-イソプロピル -4- ヨード アンフェタミン $\left.{ }^{123} \mathrm{I}\right)$ は, easy Z-score imaging system (eZIS) 内蔵の templateを用いて対象画像を一致させる ために, 線形変換と非線形変換の二つの過程を行い, 解剖学的標準化を行う. 次に smoothing 処理として, 半值幅 $(12 \mathrm{~mm}) の$ Gaussian filter を重畳処理し, 統計的 な雑音を軽減させ，個体差をなくす，また，統計処理を 行うため全脳の SPECT 值の平均值を一致させるように 乗除算して正規化する。 以上の前処置を終えたデー夕 を使い, SPMにて PD 群と PSP 群の two-sample t-test
(群間比較)を行った。血流低下の領域は $\mathrm{t}$ 検定にて有 意差を求めた。パラメータは $\mathrm{P}$ value adjustment to control(ボンフェロニー型の多重比較補正の設定)を none, threshold $\mathrm{T}$ Value ( $\mathrm{t}$ 検定の危険率の設定) を 0.001, extent threshold voxels(関連性がある一群の大き さピクセルの塊の設定)を 1000 とした。

\section{1-4 使用装置および解析ソフト}

SPECT 装置はSiemens 社製Symbia E および, Siemens 社製 E.CAM であり, デー夕处理装置は e.soft である.コリメー夕は Low-Medium Energy General Purpose(LMEGP)を使用した。解析ソフトはSPM 5 for Windows を使用し, digital imaging and communication in medicine(DICOM)のフォーマットによる 16 bits で解 析を行った.

\section{1-5 使用薬剤および撮像条件}

使用薬片：塩酸 N-イソプロピル-4- ヨードアンフェ タミン $\left({ }^{123} \mathrm{I}\right)$ 注射液, 投与量 $222 \mathrm{MBq}$, 静注後 30 分で 撮像を開始した。撮像条件は対向 2 面検出器を使用 し, energy window 15\%幅, 1 view 辺りの収集時間 を $40 \mathrm{~s}$, サンプリング角度を $5^{\circ}$ の $360^{\circ}$ 収集, matrix sizeを $128 \times 128$ とした，画像処理作成は filtered backprojection $(\mathrm{FBP})$ 法を用い, Butterworth filter[cut off 周 波数：0.35 nyquist ( 0.175 cycles/pixel), order：8] で画像 を作成した。減弱補正，散乱補正は使用していない。 また, 2 台の機種は同一の収集と画像処理である.

\section{2. 結 果}

PD 群に比べ PSP 群の血流低下は humming bird sign が 認められる領域の中脳近辺に集中していた(Fig. 1，2)。ま た，PSP 群に比べ PD 群の血流低下は, extent threshold voxels：1000では確認できなかった(Fig. 3).

\section{3. 考 察}

PD 群に比べ PSP 群の血流低下領域は, 中脳被蓋部 の委縮に先立つ血流低下と考えられた．PDは特定した 血流低下はないことが知られている。しかし，認知機 能障害を伴った場合, レビー小体型認知症と同様に後 頭葉皮質を中心とした血流低下が認められる報告があ る5). また，加齢に伴って減少する血流は健常群に比 べ，神経疾患のほとんどは早い傾向にあることが考えら れる。 PD は脳幹・基底核の変性が少ない疾患である。 PSP は, 脳内の黒質, 中脳上丘, 淡蒼球, 視床下核, 小脳歯状核などの神経細胞が減少してしまい神経原線 維変化を伴い異常構造となる，その差分から PSP 群で 


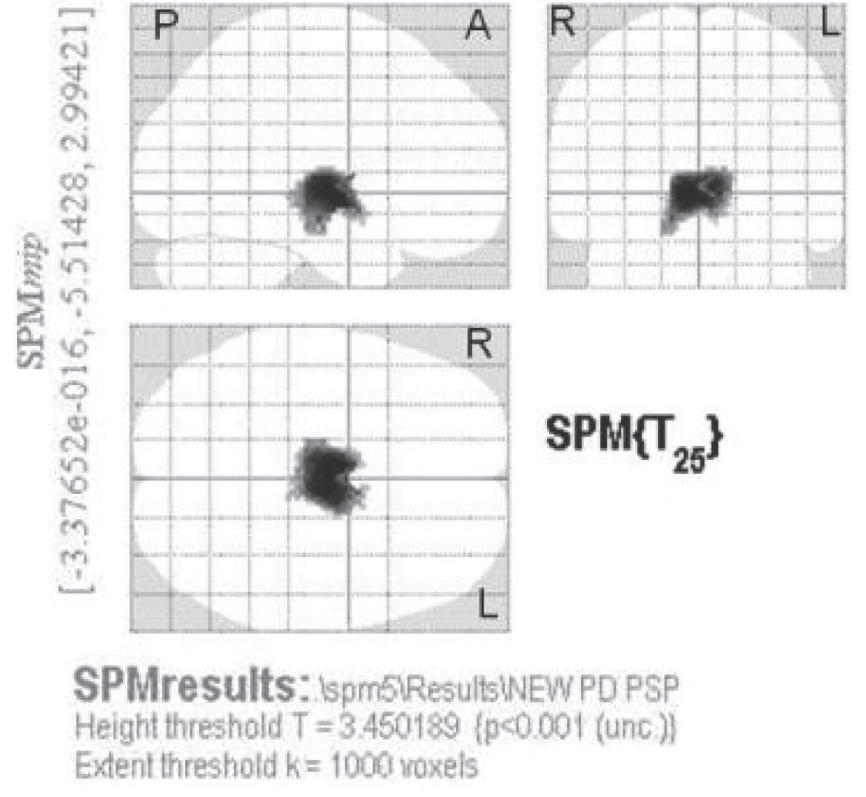

Fig. 1 Comparison of brain regions showing greater cerebral hypoperfusion in patients with PSP than in patients with PD $(p<0.001$, voxel size $>1000)$.
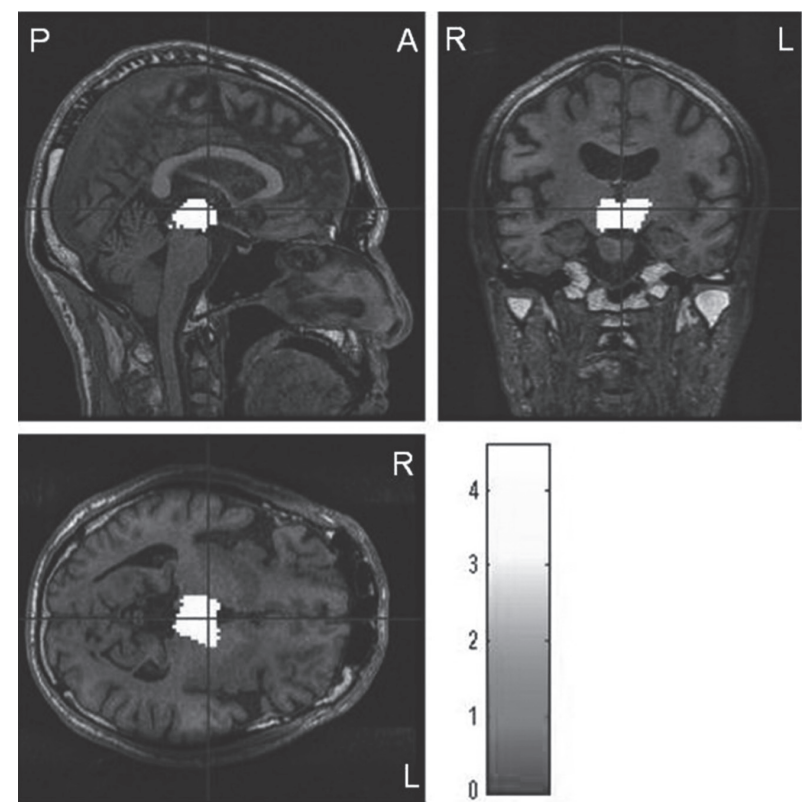

Fig. 2 Fused SPECT and MRI images.

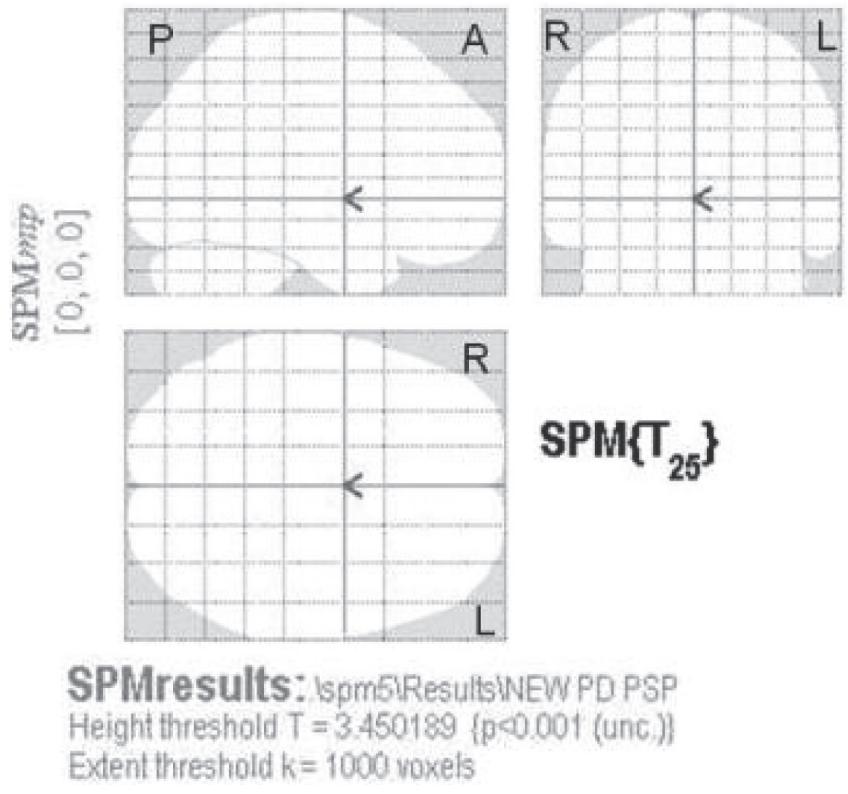

Fig. 3 Comparison of brain regions showing greater cerebral hypoperfusion in patients with PD than in patients with PSP $(p<0.001$, voxel size $>1000)$.

は中脳近辺に限局した血流低下領域を検出できたと思 われる。通常, 臨床では血流低下を観察する場合, eZIS ${ }^{6,7)}$ などを使用し, normal data base(NDB)と比較す る. Z-scoreでの表示は, Z-score mapの下限值によっ て制約をうけ表示されない領域がある場合がある。なら ば，下限值を下げて表示した場合では偽信号が増加8)し ノイズを多く含んだ画像となる。これらは脳血流の観察 に難易を要させている. どちらの設定においても気付き
にくいことと，脳全体に比べ範囲が狭いことが，今日ま で明らかにならなかったことと考えられる．PSPの有病 率が 10 万人に 4 7 人と非常に少なく, 本研究でも合 計 9 症例であるため, 軽度と中等度を一群として取り 扱った。今後はより症例を増やした検索が必要であり, 神経変性から血流低下の過程を説明することが課題で あると考えている。 


\section{4. 結 論}

Humming bird sign は有名であるが，明瞭に判断でき るのは病期の進んだ中期から末期である。これは橋・中 脳被蓋部が萎縮するのに対して，橋底部が保たれるこ とが知られている。本症例では軽度〜中等度の humming bird sign が確認された症例を提示した。本研 究によってPSP の委縮における前段階の中脳の血流低 下を捉える可能性が示唆された。

\section{謝 辞}

稿を終えるにあたり，本論文の推敲にご助言をいた だた，広島市立広島市民病院の神経内科 郡山達男医 師，田路浩正医師に感謝の意を表する。

\section{参考文献}

1) Friston KJ, Holmes AP, Worsley KJ, et al. Statistical parametric maps in functional imaging. A general linear approach. Hum Brain Mapping 1995; 2: 189-210.

2) 特集. SPM(statistical parametric mapping)の概要とその応 用。映像情報 1998; 30(18): 1095-1101.

3) Steele JC, Richardson JC, Olszewski J. Progressive supranuclear palsy: a heterogeneous degeneration invloving the brain stem, basal ganglia and cerebellum with vertical gaze and dementia. Arch Neurol 1964; 10: 333-359.

4) Kato N, Arai K, Hattori T. Study of the rostral midbrain atrophy in progressive supranuclear palsy. J Neurol Sci
2003; 210(1-2): 57-60.

5) 山崎峰雄。パーキンソニズムを呈する神経疾患の画像診 断. 日医大医会誌 $2007 ; 3(4): 167-169$.

6）松田博史. 画像データベース共有化によるアルツハイマー型 痴呆のコンピュータ診断. 老年精神医学杂倠誌 2002; 13 : 19-29.

7）松田博史. 画像統計解析法の原理と種類 eZIS. 見て診て学 ぶ痴呆の画像診断．永井書店, 大阪, 2004: 96-110.

8）山本泰司，小野口昌久. 脳血流 SPECT に扔ける統計学的 画像解析法一 eZIS と iSSP の処理の違いと注意点一. 日放 技学誌 2011; 67(6): 718-727. 